\title{
Innovation Adoption and Diffusion of Virtual Laboratories
}

\author{
https://doi.org/10.3991/ijoe.v16i09.11685
}

\author{
Krishnashree Achuthan, Prema Nedungadi, Vysakh Kani Kolil, \\ Shyam Diwakar, Raghu Raman $\left({ }^{\varpi}\right)$ \\ Amrita Vishwa Vidyapeetham, Amritapuri, India \\ raghulamrita.edu
}

\begin{abstract}
Educational technology such as Virtual laboratories (VLs) are being perceived as sustainable solutions to growing concerns related to laboratory skill training i.e. delivering quality laboratory education to a large number of students due to shortage of infrastructure and access especially in developing nations. With these VLs being an innovation for engineering education, the study of its diffusion in higher educational institutions is critical for gauging its impact. This study examines the five variables of Rogers Diffusion of Innovations theory in determining how VLs have changed or modified users through its adoption. The involvement of early adopters participating through a program called Nodal centers and their innovation decision stages are addressed. The study also analyzed the change agents as the nodal centers for diffusing the innovation in teaching and learning processes. Virtual laboratory adoption by users $(n=43600)$ over 30 months was surveyed and factors of diffusion were reported. Similar scoring in assessment factors suggested relative advantage, technology acceptance, intention of use and relevance of trialability were pertinent in users' perception of VLs. Social hubs among higher education institutions promoted early adoption through better engagement of students.
\end{abstract}

Keywords - Virtual laboratories; technology innovation and diffusion, sustainability, teaching, adopters.

\section{Introduction}

The main challenges for the educational system in many developing nations are accessibility, equity, affordability, quality and accountability [1]. To make larger contributions to knowledge economy, gross enrolment ratio must be high. In countries like India, enrolling millions of citizens into educational programs has several challenges attributed to significant shortage of adequate number of institutions, infrastructure and teaching faculty. To overcome several of these challenges, governments and agencies have been pioneering digital initiatives to bridge the divides that exist in many countries today with respect to pedagogy, quality of teaching, the lack of infrastructure and lack of access stemming from the socio-economic barriers. While it is impossible to create a trans-formative change at rapid pace, use of ICT (Information and Communication 
Technologies) can help as an integrated solution to impact millions of students and teachers overcoming language and infrastructure barriers. Several programs in the area of education i.e. building of e-learning platforms to connect expert teachers with thousands of students concurrently [2], recorded lectures by those teaching at premier institutes [3], tools and apps such as management software, smart boards, audio/visual media etc. have enhanced and modified education and educational techniques.

Like teaching theory and concepts, experimentation in laboratories is fundamental to Science, Technology, Engineering, and Mathematics (STEM) education. These laboratories can be expensive to build, maintain and expand for the scale required in many countries. A major innovation in improving poor quality laboratory education was to introduce ICT-based Virtual Laboratories (VL) [4], envisioned to supplement traditional laboratory. VLs are expected to be one of the most important future technologies in learning [5]. The advantages of using VLs include: 1) enabling acquisition of conceptual knowledge through online experimentation anytime and from anywhere and 2) working with simulations and/or equipment that allow real time connections to experimental setup and access to data, without requiring staff supervision and both of these resulting in development of experimental knowledge outside the known settings of a physical laboratory.

Given, these augment the awareness on use of VLs, mechanisms and impact assessments of its diffusion and dissemination for wider and rapid adoption into mainstream academia are non-existent in literature. There are several examples of models characterizing diffusion, acceptance, and adoption of innovations [6-8]. Diffusion of innovations are slow processes but dominant factors defining technology adoption include perceived usefulness and support [9]. While some factors for innovation diffusion are based on socio-physiological contexts, or focused on internal decision process at individual level [10,11], others are focused on users in a system [12].

The focus of this paper was to understand the diffusion and adoption of VLs in higher educational engineering institutes in India. To understand the usage diffusion and adoption of VLs, Roger's Innovation Diffusion Theory (IDT) [7] was employed. Using India's Virtual Laboratories project [4, 13], we explore capacity of the humanism in ICT as an enabler of technological diffusion with human environmental roles. In ICT environments: inclusivity of user differences, adoption rates, various types of decisions and communication channels are crucial for identifying specific attributes that hinder the diffusion process. The paper studies technology adoption and diffusion of innovation based on a nationally funded mission project involving students, professors, research staff, developers, major institutions and information flows across multiple sectors of the society involved in higher education. Now just place the cursor in the paragraph you would like to format and click on the corresponding style in the styles window (or ribbon).

\section{Background}

The widespread adoption of Information and Communication Technologies (ICT) by educational institutes (particularly in rural areas) in the last decade has led to its 
growing presence in educational settings. Several researchers report that practical experiments play a vital role in science and engineering education [14-16]. However, several barriers to laboratory education have been cited in literature, including a lack of good teachers, sufficient reagents, instruments, apparatus, ethical considerations and practical skills etc. [17-20]. In this trend, virtual laboratory (VL) is the popular ICTenabled learning tool, which is essentially a computer-based activity, where students interact with an experimental setup or conduct other activities through an user interface. The introduction of VL as an e-learning tool provides a larger opportunity for individualized learning with uninterrupted access to students across the world. The past decade has seen proliferation of virtual labs around the world in various thematic areas [21]. Since the concept of distributed online laboratories and the Wallenberg Global Learning Network [22] that included a few institutes spread across Europe and U.S., for experiment based learning, there has been a global consensus on the value of virtual labs towards active personalized learning, laboratory skill development and improved pedagogic approaches to conceptual learning [23, 24].

Due to the high demand for people with STEM skillsets, many countries have resorted to using VLs as one of their primary medium of education to provide near handson experience to their students and professionals [25, 26]. In Spain, a remote laboratories framework integrated VLs to distance learning curriculum and students were able to configure their own laboratories [27]. Several more examples of VLs developed in UK, Turkey, Germany and Ireland [28-30] have shown to facilitate self-directed inquiry-based learning. To expand the usage and development of various VLs developed across the world, the global online laboratory consortia or GOLC [31] has a created a platform to encourage and support sharable VLs for educational purposes. VLs have not only been used in institutes of higher education, but also in K-12 schools. There are over 10,000 schools in India actively using online Labs [32].

Literature shows that VL is cost-effective, could provide an interactive exploration of natural or engineered phenomena compared with physical observable experiments, enabling the acquisition of conceptual knowledge by providing clean data [23], providing access to education regardless of time and geographical barriers, and nurturing development of collaborative and knowledge creation skills [33]. Literature suggests that use of technologies like VL play an important role to promote students' conceptual change [34], reflective learning [20] reduction of alternate conception [35] and cognitive load [36]. With educational institutes increasingly gravitating towards ICT education usage across India, it is critical that educators and administrators explore and understand the characteristics and motivations of both groups of people who adopt and reject $\mathrm{VL}$ in science and engineering education.

Technology adoption is considered the most important event of the 20th century [37]. The internet is the commonest communication and research access method for technology. Diffusion of innovations theories study community members' acceptance and assimilation of these innovations. Comprehending technology adoption behaviour and diffusion of innovation play a significant role in determining acceptance factors and new adopters' behaviour regarding new technologies. Adopting new innovations has been studied extensively determining key factors that influence technology acceptance [38]. These ideas form a general framework for assessing the social impact of 
technologies on people and provide insight into the technology features that may influence specific adoption patterns. Research on technology innovations in education suggests technology design, instructional methods, students' usage characteristics and other factors contribute to the effectiveness of technology adoption (e.g., [39, 40]).

Like in other cases, many factors including roles of students and teachers, technology, cost, access, media, efficacy of users, resources, social dimension etc., need to be evaluated at the same time while assessing diffusion of virtual lab in education. Although there have been many models studying innovation, some have been based on social-physiological contexts and relate to internal decision processes at an individual level [41-43], some focus on aspects of innovation and relate diffusion of new innovations among users in a system [44, 7]. Another paper [45] had suggested adoption of ideas based on Roger's [7] diffusion of innovation theory has been widely applied in disciplines such as education, sociology, agriculture, marketing, and information technology etc. The diffusion of innovation theory [7] may be appropriate for exploring the adoption of virtual laboratories. The process of adopting new innovations has been dissected thoroughly by many over decades [47]. In this paper, Rogers' diffusion theory [46] was used to analyze the acceptance and implementation of virtual laboratory in institutions of higher learning in India.

According to Roger's innovation diffusion theory [46], four components affect the rate of diffusion. Diffusion of new ideas, practices and technology happens over time when an innovation trickles down through specific networks to members of a social system or potential adopters who then communicate by creating and sharing information by any means. The five factors that have been known to impact the characteristics of an innovation are relative advantage, compatibility, complexity, trialability and observability. It has been suggested that three points dependent on time as a factor include innovation-decision process, innovativeness of an individual and an innovator's rate of adoption in a system.

A key advantage of using the Roger's diffusion theory was that it related inhibition of the diffusion process to effective practices and conditions that facilitate diffusion [48].

\section{Development and Dissemination of Virtual Labs Through Nodal Centers}

\subsection{Virtual laboratories project}

In 2009, a consortium of premier Indian institutes (called Partner Institutes) were brought together by the Government of India to conceptualize and build Virtual Laboratories (Figure 1). This consortium proposed building a set of 20 virtual labs (with each lab containing 8 to 10 experiments each) in areas related to science and engineering. 


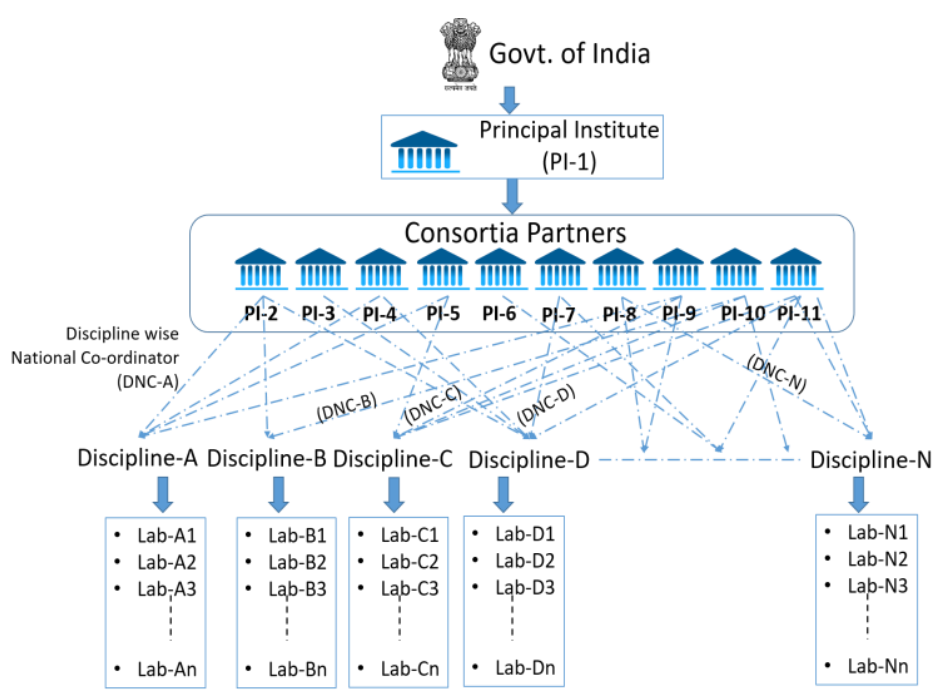

Fig. 1. VL Project - Development and deployment by partner institutes. A top-down organisation for the project involving the funding agency to consortia partners to disciplines and topics.

The development of VLs involved three levels of coordination (Figure 2). Subject Matter Experts (SMEs) provided the content and design of experiments based on national curriculum syllabi. Principal Institute Coordinators (PICs) coordinated the development of all VLs and interfaced with the multimedia team within their institute and Discipline wise coordinators (DNCs) held the role of ensuring most relevant labs in their respective disciples were developed by SMEs from various partner institutes. The two-level leadership role within partner institutes is described here [13]. All these three types of faculty were innovators and accomplished consolidation of labs and experiments through series of discussions and research that would benefit over 500000 engineering graduates across the country.

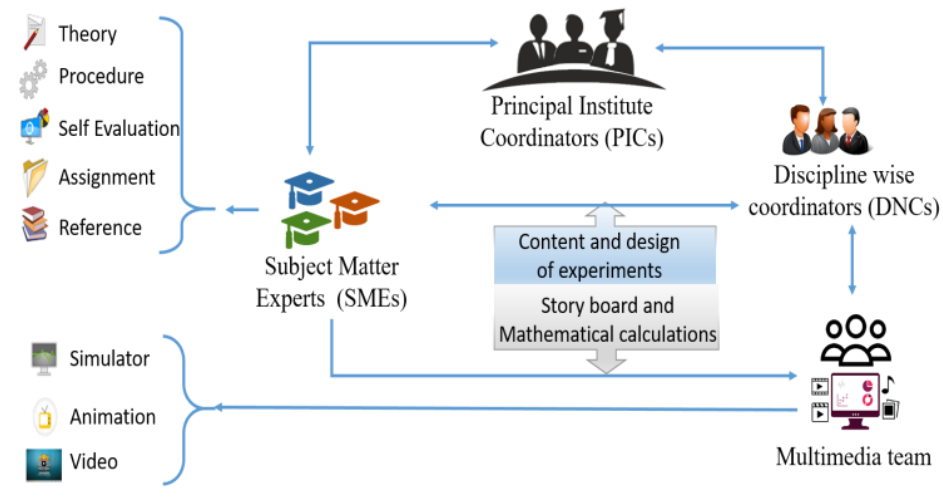

Fig. 2. Virtual Experiment Development Framework. 


\subsection{Choice of content and development process}

The criteria for content was based on 1) common experiments across syllabi of public and private universities 2) experiments that students repeated due to difficulties in observation or concept perception (e.g. Millikan's oil-drop experiment required students to observe a green drop to fall and took several trials to observe [49]. The development of an experiment involved interviewing faculty members who identified the experiments to convert and to ensure the learning objectives were central to the development of VLs. This was then followed by story-boarding, video recording of the actual experiment followed by creative artists animating the sequence of steps and rendering an animated experiment. There were three types of VLs i.e. animation-based, simulation-based and remote-controlled VLs that were considered in this study. Animationbased VL involved a set of multimedia enhanced emulations while simulation-based $\mathrm{VL}$ involved mathematical and phenomenological models. In the case of remote labs, users operated and controlled experiments online. VLs are freely available at http://vlab.amrita.edu and at http://vlab.co.in.

\subsection{Dissemination of VLs and assessments}

To effectively allow early adopters of innovation in their regional areas, a nodal center program was created for dissemination and involved induction of science and engineering education institutes (Figure 3). With the interest of the partnering institutions teaching members, the induction of nodal centers ensured support and assessment tools. Training to the participating faculty members was a part of the nodal center program. The platform's assessment tools involved multiple choice questionnaires and descriptive questions for institutions and teachers to assess student's perception of technical concepts and to report the user experience [20,50]. A nodal center conference was organized annually for additional hands-on training and opportunities to interact with faculty members and provide feedback. Students and teachers at the nodal centers are being supported periodically with training sessions online and/or onsite. Assessment instruments have been developed for various experiments and are shared with the nodal centers as well for testing of learners. VL assessment include conceptual and user-experience related questions. A combination of MCQs (multiple choice questions), and descriptive questions have been engaged to perceive grasp of technical concepts and Likert scale questions to report the user experience.

The modality of usage and frequency are extremely important in terms of impacting the learning outcomes. Studies have shown VLs when used as pre-lab sessions have reduced the time students take to complete physical lab experiments [51]. The cognitive load of students that were supplemented with VLs was much lower than those that did not get exposed to VLs and the former also outperformed when assessed on conceptual knowledge gain.

In 2012, the Ministry of Human Resources development (MHRD) officially launched a bouquet of 80 VLs with 640 experiments. At the launch, 20 institutes had committed to becoming nodal centers and use VLs as part of their curriculum. 


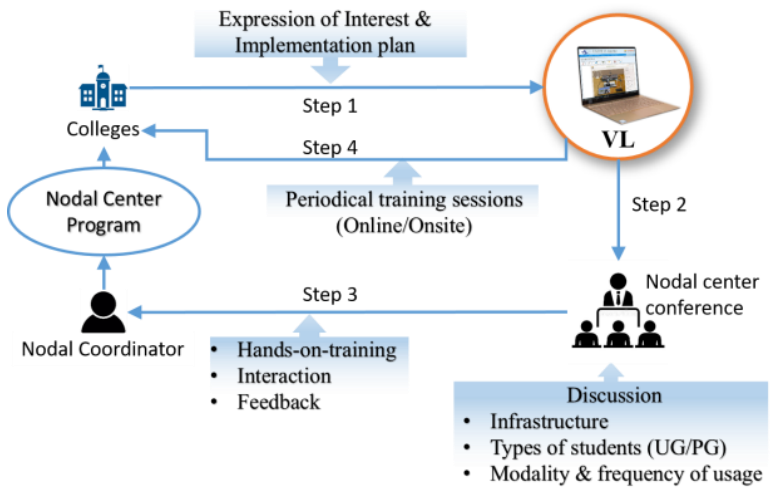

Fig. 3. Nodal center management

\section{Diffusion of Innovations Theory and Virtual Labs}

\subsection{VL adopter categories}

In our virtual laboratories, five types of adopter were identified: development partners from universities and institutes of national importance and ranked research-intensive private universities were innovators $(2.5 \%)$. Nodal partners became early adopters (13.5\%) especially from ranked colleges, large public or state universities and private universities. Combining both categories brought $16 \%$ and these two groups typically generated all the information of the product system. Early majority (34\%) included smaller institutions like affiliated colleges that adopted new ideas and implemented them but did not show unique leadership. The category of institutions that tried innovation after many had already incorporated and tested them became the late majority (34\%). With similar characteristics, both, early majority and late majority comprise $68 \%$ of the adopter categories. Few institutions seldom wanted to or came forward to participate in innovation adoption and were part of the laggards (16\%), insignificant diffusers of innovation.

Institutes were categorized based on the expression of interest (EOI) received after the communications from innovators. Figure 4 represents the different categories of adopter institutes based on the mode and number of communications. There are several communications between innovators and adopters included a) website notification, b) E-mail, 3) postal letters, 4) SMS, and 5) telephone calls. According to the current number nodal centers (110) we were able to classify them to different categories. The institutes signed as nodal center of VL after the website notification (trail \#1) were grouped as 'early adopters'. 16 institutes from different states were in the first group. In the second trial, \#2, we included e-mail also in the communication along with website notification and 38 institutes from different stated were signed as nodal centers. Grouped these 38 instituted as 'early majority'. In the third trial, \#3, we included postal letters, SMS and telephonic calls into the communications and another 38 institutes from 
different states were signed as nodal centers. These instituted were grouped as 'late majority'. Laggards (18 institutes) took more than 5 times of all types of communications (website notifications, e-mails, postal letters, SMS and telephonic conversations) between innovators and them to adopt the innovation. Institutes in the 'laggard' category were mainly Govt. institutions.

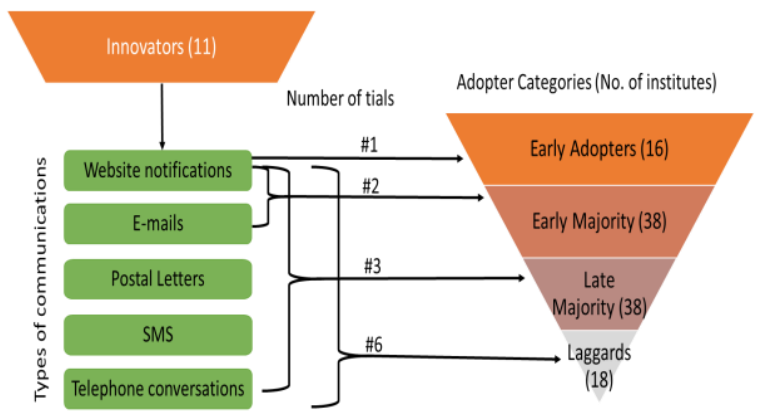

Fig. 4. Adopter categories based on the number of communications from developer institutes.

\subsection{Perceived attributes of innovation}

As per the theory of innovation, 'the perceived attributes of an innovation are one important explanation of the rate of adoption of an innovation' and states that an innovation is perceived based on certain adoption related factors. In our categorization, with faster rate of diffusion, the adopters may show 1) having advantage relative to other innovations 2) compatibility with existing practices and values 3 ) not being very complex 4) tried on a limited basis before adoption, and 5) offered tangible results. Based on Dayton [12], these attributes, relative advantage, compatibility and complexity were relevant to test in reference to VL adopters. VL as an ICT innovation was analyzed based on its relative advantage (RA), compatibility (CO), ease of use (EU), trialability (TR), and observability (OB).

According to Roger's theory, i) VLs must include an advantage relative to other learning methods; ii) VLs must be compatible with existing practices and values; iii) VLs must not be complex for students and teachers [50]; iv) VLs may be tried before adoption, like in the case of early adopters; v) usage of VL should show observable results. Although all of the 5 attributes were assessed, VL adoption related closely to relative advantage (students using VLs outperforming those with classroom teaching alone, see $[20,50]$ ) compatibility (perception that performing experiments under VL will lead to similar experiences in physical labs, see [52]) and complexity (degree of ease of use, see [53]) as key attributes for diffusion [54].

Based on an established measurement instrument [44], a five-point Likert scale questionnaire was provided to 43,300 students and 300 faculty members from 58 nodal centers over a 30-month period to assess their perceptions about VL. Five independent variables included Relative Advantage (RA), Compatibility (CO), Ease of Use (EU), Trialability (TR), and Observability (OB) were studied and internal consistency was 
measured using Cronbach's alpha (Table 1). Cronbach Alpha values were in the range of 0.77 to 0.87 confirming the reliability of measures in the assessment.

Table 1. .Internal consistency, mean and SD of survey instruments

\begin{tabular}{|c|c|c|c|c|c|}
\hline No. & Items & Factors & Mean & SD & $\boldsymbol{\alpha}$ \\
\hline 1 & $\begin{array}{l}\text { I am able to understand the experiment properly by performing } \\
\text { it in virtual lab }\end{array}$ & \multirow{6}{*}{ RA } & \multirow{6}{*}{4.35} & \multirow{6}{*}{0.7} & \multirow{6}{*}{0.9} \\
\hline 2 & $\begin{array}{l}\text { Performing the experiment in virtual lab increases my confi- } \\
\text { dence level for performing the same in real laboratory environ- } \\
\text { ment. }\end{array}$ & & & & \\
\hline 3 & $\begin{array}{l}\text { Performing the experiment in virtual lab has decreased my anx- } \\
\text { iety with lab experimentation while helping me learn new con- } \\
\text { cepts. }\end{array}$ & & & & \\
\hline 4 & Virtual lab helps me to understand at least three concepts. & & & & \\
\hline 5 & Virtual Lab has helped improve my performance in physical lab & & & & \\
\hline 6 & Overall, I find Virtual Lab useful for my learning & & & & \\
\hline 7 & Experiments in virtual lab are easy to understand. & \multirow{4}{*}{ EU } & \multirow{4}{*}{4.34} & \multirow{4}{*}{0.7} & \multirow{4}{*}{0.8} \\
\hline 8 & $\begin{array}{l}\text { Using Virtual Lab in my learning enables me to accomplish } \\
\text { physical lab tasks quickly }\end{array}$ & & & & \\
\hline 9 & $\begin{array}{l}\text { Learning of experiments through virtual lab was fun and inter- } \\
\text { esting. }\end{array}$ & & & & \\
\hline 10 & Overall, I find the Virtual Lab easy to use. & & & & \\
\hline 11 & $\begin{array}{l}\text { The organization of the contents in virtual lab is excellent in } \\
\text { aiding my learning. }\end{array}$ & \multirow{3}{*}{$\mathrm{CO}$} & \multirow{3}{*}{4.29} & \multirow{3}{*}{0.8} & \multirow{3}{*}{0.8} \\
\hline 12 & My self-learning skills has improved by using Virtual Lab. & & & & \\
\hline 13 & $\begin{array}{l}\text { In a Virtual Lab, I find it easy to get the system to do what I } \\
\text { want it to do. }\end{array}$ & & & & \\
\hline 14 & I like the fact that I can try and practice using Virtual Labs. & \multirow{2}{*}{ TR } & \multirow{2}{*}{4.31} & \multirow{2}{*}{0.8} & \multirow{2}{*}{0.8} \\
\hline 15 & It would be easy for me stop using the Virtual Labs & & & & \\
\hline 16 & I find it easy to see others performing the tasks in a Virtual Lab. & \multirow{2}{*}{$\mathrm{OB}$} & \multirow{2}{*}{4.31} & \multirow{2}{*}{0.7} & \multirow{2}{*}{0.8} \\
\hline 17 & I find Virtual Lab easy to observe and interact with & & & & \\
\hline
\end{tabular}

To assess any gender differences in the attitude towards VL, an independent-samples t-test was conducted. The assessment found significant differences between male and female responses (Table 2).

Table 2. Independent sample $t$-test results of the gender differences in the attitude towards VL

\begin{tabular}{|c|c|c|c|c|}
\hline Category & Gender & Mean & $t$ & $p$ \\
\hline \multirow{2}{*}{ RA } & Male & 26.06 & \multirow{2}{*}{-3.183} & \multirow{2}{*}{0.001} \\
\hline & Female & 26.17 & & \\
\hline \multirow{2}{*}{ EU } & Male & 17.31 & \multirow{2}{*}{-5.596} & \multirow{2}{*}{0.000} \\
\hline & Female & 17.45 & & \\
\hline \multirow{2}{*}{$\mathrm{CO}$} & Male & 12.92 & \multirow{2}{*}{-5.929} & \multirow{2}{*}{0.000} \\
\hline & Female & 13.03 & & \\
\hline \multirow{2}{*}{ TR } & Male & 8.65 & \multirow{2}{*}{-5.638} & \multirow{2}{*}{0.000} \\
\hline & Female & 8.72 & & \\
\hline \multirow{2}{*}{ OB } & Male & 8.64 & \multirow{2}{*}{-7.024} & \multirow{2}{*}{0.000} \\
\hline & Female & 8.73 & & \\
\hline
\end{tabular}


VL innovation attributes were measured using a five-point Likert-scale ('strongly disagree' - 1 to 'strongly agree'- 5). Among student users, VL adoption was attributed equally for all five indicators over standard pedagogical practices. (see Table 1).

Relative advantage ( $4.35 \pm 0.72$ off 5) was positively correlated to usage of VL in education. Ease of Use's high value ( $>4.3$ off 5 ) suggested good acceptance of VL by student adopters. This also suggested that the analyzed user subset could be early adopters. Compatibility ( $>4.2$ off 5 ) was positively associated with an adopter's intention to use web-based tools in education. Similarly, trialability and observability scores indicated user intent augmented subsequent continued usage of the ICT innovation.

\subsection{Types of innovation-decision}

Initially National Mission on ICT (NME-ICT), acting on behalf of Govt. of India, used their authority and decided to develop the VL project. Select premier institutions were asked to send their proposals and a committee was formed to review and approve them. 12 institutions were identified to develop the VLs. These were called Participating Institutes (PI). These PIs were the innovators. One of the PI was chosen to be the National PI.

Subsequently, the PIs got together, involved faculty members from their respective institutions and decided on the allocation of experiments, funding, more or less started making collective decisions.

Once the development of VLs reached a critical mass and PIs tested them in their own institutions, concept of nodal centers was developed to scale the VL project across the nation. It was left to nodal centers (optional) to decide on how much they want to use VLs in their institutions.

\subsection{Communication channel}

Effective communication strategies enhance innovation diffusion $[55,56]$. Communication of product features and information on its best usage and resulting advantages with the end beneficiary in mind helps improve their attitude towards technology, clarity and acceptance [55-58]. Since higher education, several modes of communication channels were pursued in order to reduce perceived risks and uncertainties in its integration into the curricula (Figure 5). A multi prong approach that included both a top level and intermediary advocacy levels were pursued. This included: i) awareness building through presentations on the national mission for education and VL project at prominent conferences and meetings with the university rectors (vice-chancellors), ii) dissemination of information to heads of schools and teachers on features, step-by-step demonstrations, hands-on training workshops and faculty development programs (FDP) (see Table 3) at nodal centers, iii) sharing of results from research studies on VLs, 4) regular online demos of experiments for new students with feedback and interactive sessions 5) employing multimedia components i.e. videos and animations for self-learning and demonstration of concepts (Figure 5). The frequency of regular training provided to nodal centers significantly reduced with time as their number of trained faculty members increased. Due to the diverse thematic areas in VLs, independent 
effort was critical to align potential adopters. The Table 3 gives details of number of workshops and training given to users over a five-year period by a premier institute.

Table 3. Activities over five years by a partner

\begin{tabular}{|c|l|c|c|}
\hline Sl. \# & \multicolumn{1}{|c|}{ Activities } & Quantity & \# Users \\
\hline 1 & Number of workshops at Partner Institute & 14 & 1045 \\
\hline 2 & Number of workshops at Nodal Centers & 15 & 3267 \\
\hline 3 & Online demonstrations & 32 & 1209 \\
\hline 4 & Hands-on training sessions & 19 & 2058 \\
\hline & Total Count of Workshops & 87 & 7726 \\
\hline
\end{tabular}

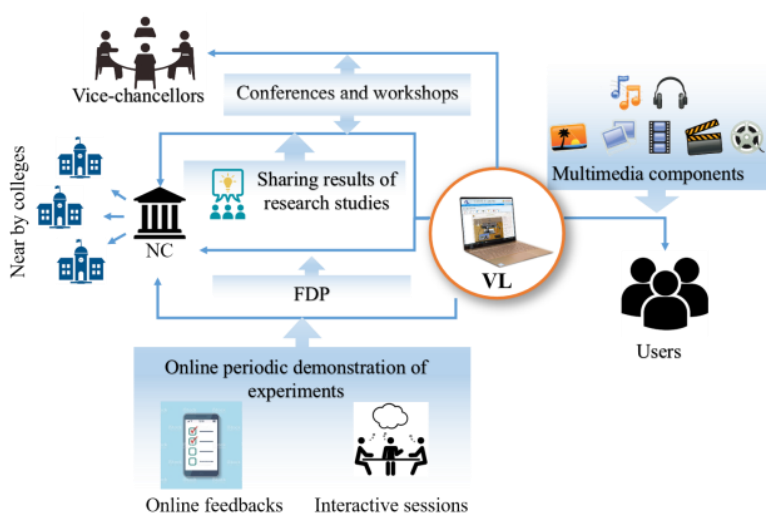

Fig. 5. Communication channels for disseminating virtual laboratories

\subsection{Social system for VL diffusion and change agents}

Hubs established by developers (early adopters) of VLs with partner institutes (nodal centers) became the main accelerators for the rate of adoption and information flow [59] (Figure 5). However, VL workshops at developer institutes had three to four times higher response and attendance than at partnering nodal centers. The interpersonal influences play a role towards adoption of VL and can be influential and normative by nature. Individuals influence innovation-decisions with the assistance of opinion leaders $[48,60]$ act as change agents. In our adoption, key change agents were lab developers, principal institute coordinators, discipline-wise national coordinators and nodal center coordinators who were passionate about bringing better pedagogical processes in their respective institutions and the community. Key steps that may assure better adoption would be recognition to institutions using such innovations, incentives such as promotions, financial allowances and institutionally highlighting positive outcomes of student performances resulting in their constructive feedback of faculty and the institute. The VL design involved making user interactivity a key component as technology changes also drove adoption. For adoption, across devices, no advanced technical ability was to be required to understand and use the interfaces. For example, using tabs to navigate along with buttons, pull-down menus and sliders to choose the experimental 
variables, voice assisted videos for educating concepts to student users acted as technology features promoting better adoption.

\subsection{Innovation-decision stages}

The stages of innovation diffusion [7] included knowledge communication, persuasion, decision, implementation and confirmation (Figure 6). Several studies have indicated the importance and need for effective communication strategies in order to enhance innovation diffusion. In the knowledge stage of innovation decision cycle, a formal National Launch of VLs by the Ministry of Education ignited the flow of information through the press. This was followed by communication of the objective of VL project through conferences, online media, media campaigns and word-of-mouth. It also included meetings with departmental chairs, faculty members and researchers.

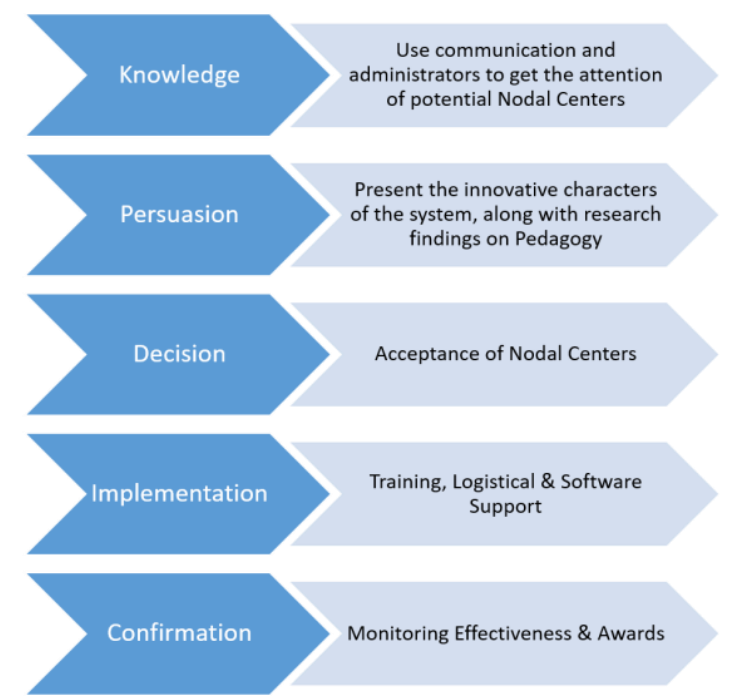

Fig. 6. VL Diffusion model

Persuasion stage involved presenting advantages of usage and assessment of curriculum-based exercises and highlighting the student-instructor features of hosting platforms [61] The impact on improved teacher and student experiences was enhanced in VLs with 1) human-centric intuitive user-interfaces that aesthetically mimic reality and are scientifically accurate in simulated experiments 2) real-time data generated while viewing the experimental run in remotely triggerable experiments that are unavailable to most institutions due to their prohibitive costs. In addition to exposure of possible experiments, access to an authoring platform VLCAP [61] was given to allow faculty to create new experiments, assessments, scheduling of experiments along with reports on usage and learning. In summary, the interactive sessions encompassing presentation of features, opportunity for teachers to experiment with themselves most critical to their decision to use VLs. 
Decision stage involved nodal centers creating usage hubs connecting activity and establishing technical support scenarios (Figure 7). Once the intention to use translates from cognitive to affective thinking, an expression of interest (EoI) is requested from each institute that serves as a formal agreement between the partner institutes and nodal centers. A systematic plan was laid out with each institute that includes VLs in multiple disciplines. The plan included decisions on 1) infrastructure that includes computers, internet bandwidth 2) curriculum fit and types of students that could use VLs for i.e. under graduate or post graduate and their year of study 3 ) modality and frequency of usage i.e. as pre-lab or post-lab or take-home assignments to supplement theory sessions. Engaging in planning sessions with nodal centers helps them gain clarity on usage, overcome uncertainties resulting in significantly higher levels of comfort.

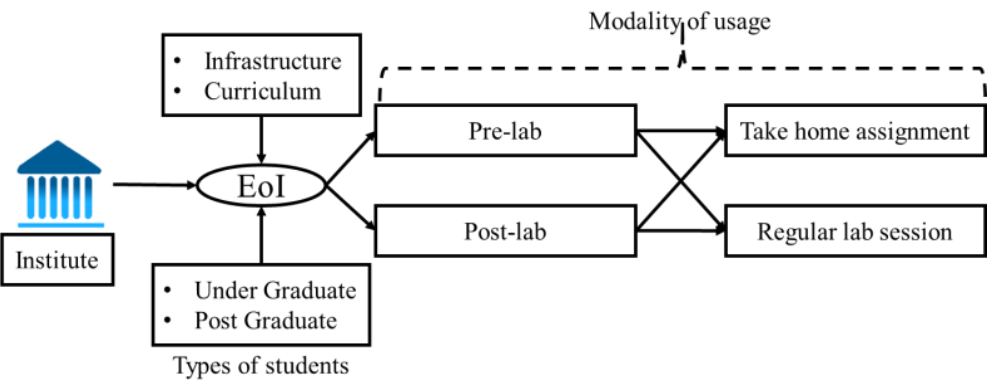

Fig. 7. Decision stages of VL

Implementation stage involved regular communication with nodal centers on following through with co-designed plans and asserting student and user feedback. As nodal centers are leaders in their communities, their usage as well as mentoring they provide to local institutions are supported and recognized with national awards. The awards include 1) Best Engineering Nodal Center, 2) Best Arts and Sciences Nodal Centre, 3) Best Nodal Coordinator. Figure 8 a below shows the number of institutes from different states in India have adopted VL into their curriculum. Tamil Nadu and Kerala have most number of institutes and $70 \%$ of the total nodal centers are engineering colleges. 48.18\% and $27.27 \%$ institutes from Tamil Nadu and Kerala respectively adopted VL into their education. Every year approximately 15-20 new institutes became as Nodal center (Figure 8). The survey shows average number of student-faculty ratio at nodal centers is $33: 1$ ratio. 


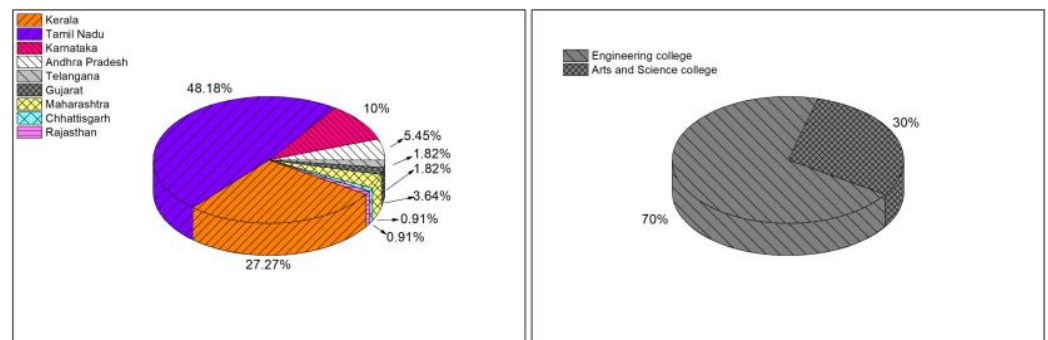

a) Number institutes from various

b) types of institutes states in India

Fig. 8.

Confirmation stage included use of standard assessment instruments and tools for teachers and users to confirm changes attributed to VL adoption. Systematic approaches to both qualitative and quantitative assessment are emphasized (Figure 9). The instruments evaluate conceptual and experimental skills using a combination of MCQs (multiple choice questions), and descriptive questions to gauge grasp of technical concepts. Likert scale questions are used to report their respective user experience.

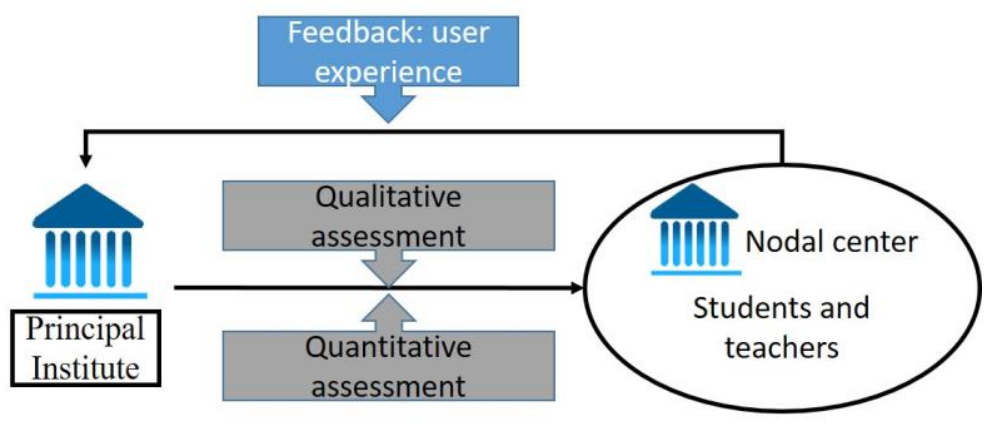

Fig. 9. Confirmation stage

\subsection{Critical mass of $\mathrm{VL}$ adoption}

Critical Mass of Adoption can be defined as a stage wherein at a given point, enough adopters have "adopted innovation such that the innovations further rate of adoption becomes self-sustaining" [7]. Until the critical 'mass' was achieved the rate of VL adoption remained slow [62], however adoption accelerated after the critical mass was achieved. Critical mass may be attained if users had a high rate of trialability and the threshold level for critical mass varied between 10-25\% [63]. With VL adoption becoming sustainable and increased users and centers testing virtual laboratories, the critical mass was based on the number of partnering institutes and outreach to students by nodal centers. The increase in numbers of VL usage was also related to number of nodal 
center partners (Figure 10). A 25-fold increase in nodal centers was observed when compared to 2011 and more than a million active users are part of this program using VL today.

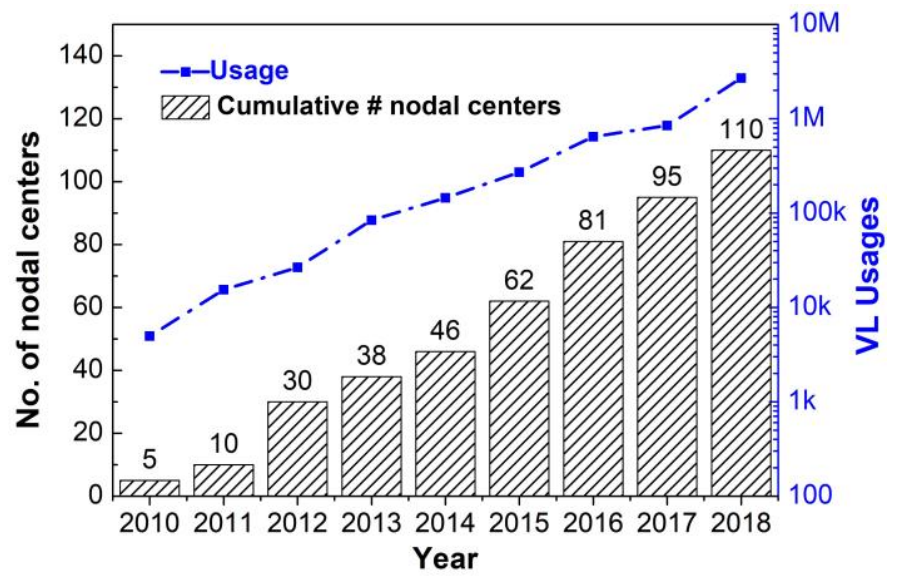

Fig. 10. Year-wise VL usage in millions (right axis) and number of NCs (left axis)

The curve of adoption of VL among students and teachers had a logistic ' $\mathrm{S}$ ' shape, with an early slow phase, a rapid middle phase with widespread, and a slow third phase with incomplete penetration in the end. To know the approximate year of the third phase of ' $\mathrm{S}$ ' shaped curve, we analyzed the adoption of VL using the Bass diffusion model [64]. According to Bass model, diffusion of technology into new users will be increases exponentially and appeared to be steady at certain level. While comparing the current trends of increasing the new user of virtual labs with Bass model (Figure 11), it predict that the diffusion of VL will cover approximately 2 million users by 2031 .

$$
a(t)=M p+[q-p] A(t)-\frac{q}{M} A(t)^{2}
$$

In the Bass model above, $p$ was the coefficient of innovation and does not interact with the cumulative adopter function $\mathrm{A}(\mathrm{t})$. Also, $t$ represented time from VL launch and was non-negative. The variable $\mathrm{a}(\mathrm{t})$ represented the adopters or adoptions at time $(\mathrm{t})$. The letter $q$ was the coefficient of imitation and reflected the influence of previous adopter. In this case, the diffusion of VL happened with the influence of previous adopters like the early nodal centers. $M$ was the ultimate number of adopters (i.e. 2 million users). The coefficients $p$ and $q$ were calculated using regression analysis of the actual data. The data obtained from the Bass model analysis using Bass model differential equation predicted that the adoption of VL by 2 million users with $p=0.002$ and $q=0.790$ will cover by 2031 (Figure 11 ). 


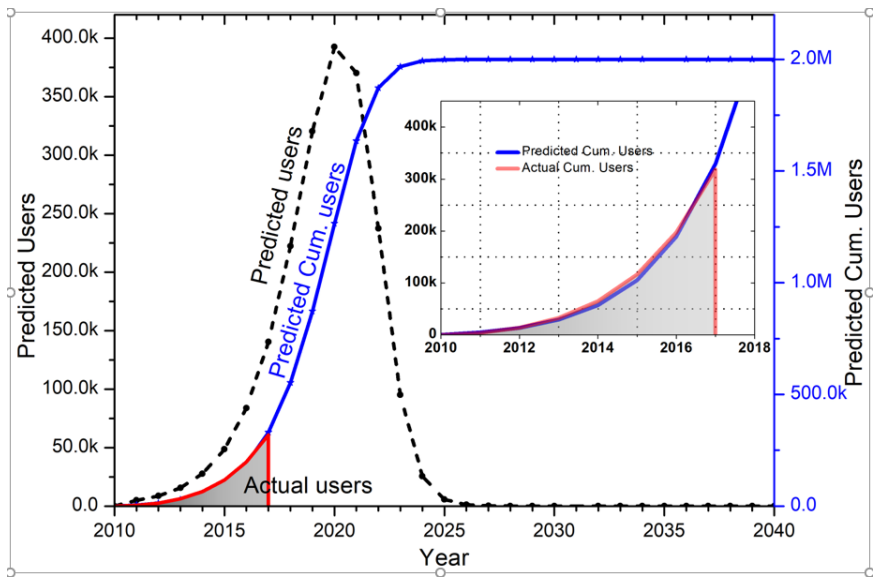

Fig. 11.Prediction of adoption of VL using BASS model. Black dotted line represents the predicted users, blue dotted line represents the cumulative number of the predicted users and red line represents the cumulative number of the actual users in each year. Inset shows the cumulative number of actual user and predicted users from 2010 to 2017.

\section{Discussion}

Implementing an education technology such as VL and diffusion in higher education closely involve adopters and methods. The paper highlights how diffusion of VL has been implemented in India through nodal center program and how adoption stages of persuasion, decision, implementation and confirmation relied on the network created by the innovators connected to early adopters. Diffusion theory facilitates the investigation of process dynamics between innovators and adopters relating to adopting behaviors and attributing complex play between technology, social systems and communication. Communications and social networks are prominent for VL diffusion. The adoption depended on how developers and nodal centers implemented VLs into daily usage with their students. Engagement of students by partner institutions allowed faster rate of adoption.

The most contributing communication channel was the social hub established between innovators and early adopters through the nodal center program and use of other channels may not be as reliable. Contextual and situational factors established by innovators and early adopters may aid innovation implementation although information innovations must clearly have an advantage over existing resources. Compared to nodal center program, VL deployment suggests while implementing innovators only half the number of participants may play a role in convincing others to adopt an innovation and employ VL in their practice. This includes colleagues, nodal center partners, institutions of repute and motivated students and teachers.

For populated countries like India, survey involving 43600 users may indicate current trends in adoption of ICT innovations. The survey suggested trends in adoption relate to the degree of innovation and design as natural promoters of VL. Direct feedback from students suggests better graphical interfaces, self-learning functionality 
motivate student users. Our assessments did not reveal any gender bias in the responses and all components of diffusion were distributed evenly indicating strong contributions of interactions, perceptions and experience. The more VL integrates or coexists with existing pedagogical system, past experiences and the needs of potential adopters, the greater are its prospects for diffusion and adoption. $\mathrm{VL}$ is popular with students who want try experiments many times especially during examination periods. This suggests technology platforms may need to account usage time to assess behavior but there is no significant indication in the literature regarding time users need to spend with an innovation prior to making the decision to adopt it into regular practice.

\section{Conclusion}

As an innovation, virtual laboratories promote resilient, inclusive and sustainable approach to supplement knowledge and training resources and common limitations to laboratory skill training. In general, VLs are perceived as having relative advantages, being more compatible, less complex, observable, and trial-able and connected through accessible communication channels. However, VLs may need constant adaptations to improve its relative advantages over current resources and practices such as community-centered contexts, relevantly updated user interfaces and novel mechanisms of automated assessments. In this direction, we are extending this study towards long-term maintenance of adoption behavior and the behavioral adaptations among regular users.

\section{$7 \quad$ Acknowledgement}

This work derives direction and ideas from the Chancellor of Amrita Vishwa Vidyapeetham, Sri Mata Amritanandamayi Devi. The work was funded by Virtal Labs Phase III project of National Mission on Education through ICT, Ministry of HRD, Government of India and by Embracing The World Research-for-a-cause Initiative. Authors would like to thank Saneesh P. F., Mithun Haridas and Sharanya M for their help in the study.

\section{$8 \quad$ References}

[1] MHRD (2016) Human resource development challenges URL http://mhrd.gov.in/ sites/upload_files/mhrd/files/hrd_challenges.pdf

[2] Bijlani K, Krishnamoorthy S, Rangan V, Venkataraman R (2011) A-view: Context aware mobile e-learning for the masses. In: International Conference on Mobile Wireless Middleware, Operating Systems, and Applications, Springer, pp 1-14. https://doi.org/10.1007/ 978-3-642-30607-5_1

[3] NPTEL (Online) Nptel online courses URL https://onlinecourses.nptel.ac. in/

[4] Achuthan K, Sreelatha K, Gangadharan R, Appukuttan S, Ranganatha J, Sambhudevan S, Mahesh S, Surendran S, Diwakar S, Nedungadi P, et al. (2011) The value@ amrita virtual labs project: Using web technology to provide virtual laboratory access to students. In: 2011 
IEEE Global Humanitarian Technology Conference, IEEE, pp 117-121. https://doi.org/10.1109/ghtc.2011.79

[5] NMC (2016) 2016 highere ducation edition $\mathrm{nmc}$ horizon report URL https://www.nmc.org/publication/nmc-horizon-report-2016-higher-education-edition/. https://doi.org/10.21125/edulearn.2017.0572

[6] Kratochwill TR (2005) Theories of change and adoption of innovations: The evolving evidence-based intervention and practice movement in school psychology. Psychology in the Schools. https://doi.org/10.1002/pits.20086

[7] Rogers EM (2003) Diffusion of Innovations, 5th edn. Free Press

[8] Hall GE, Loucks S (1978) Teacher concerns as a basis for facilitating and personalizing staff development. Teachers college record 80(1):36-53

[9] Talukder M (2012) Factors affecting the adoption of technological innovation by individual employees: An australian study. Procedia-Social and Behavioral Sciences 40:52-57. https://doi.org/10.1016/j.sbspro.2012.03.160

[10] Fishbein M, Ajzen I (1977) Belief, attitude, intention, and behavior: An introduction to theory and research

[11] Davis FD (1989) Perceived usefulness, perceived ease of use, and user acceptance of information technology. MIS quarterly pp 319-340. https://doi.org/10.2307/249008

[12] Dayton D (2006) A hybrid analytical framework to guide studies of innovative it adoption by work groups. Technical Communication Quarterly 15(3):355-382. https://doi.org/10. 1207/s15427625tcq1503_5

[13] Raman R, Achuthan K, Nedungadi P, Diwakar S, Bose R (2014) The vlab oer ex $\neg$ perience: Modeling potential-adopter student acceptance. IEEE Trans Education 57(4):235-241. https://doi.org/10.1109/te.2013.2294152

[14] Heradio R, de la Torre L, Galan D, Cabrerizo FJ, Herrera-Viedma E, Dormido S (2016) Virtual and remote labs in education: A bibliometric analysis. Computers \& Education 98:14-38. https://doi.org/10.1016/j.compedu.2016.03.010

[15] Winkelmann K, Scott M, Wong D (2014) A study of high school studentsâĂŹ perfor $\neg$ mance of a chemistry experiment within the virtual world of second life. Journal of chemical education 91(9): 1432-1438

[16] Diwakar S, Achuthan K, Nedungadi P, Nair B (2011) Enhanced facilitation of biotechnology education in developing nations via virtual labs: analysis, implementation and case-studies. International Journal of Computer Theory and Engineering 3(1):1 https://doi.org/10. 7763/ijcte.2011.v3.275

[17] Bell J (1999) The biology labs on-line project: Producing educational simulations that promote active learning. Interactive multimedia electronic journal of computer-enhanced learning 1(2): $1-10$

[18] Tüysüz C (2010) The effect of the virtual laboratory on students' achievement and attitude in chemistry. International Online Journal of Educational Sciences 2(1)

[19] Kisnieriene V, Beitas K, Sakalauskas V, Daktariunas A (2008) Information technologies for biology education: computerized electrophysiology of plant cells. Informatics in education 7(1):91

[20] Achuthan K, Francis SP, Diwakar S (2017) Augmented reflective learning and knowledge retention perceived among students in classrooms involving virtual laboratories. Education and Information Technologies 22(6):2825-2855. https://doi.org/10.1007/s10639-017-9626$\underline{\mathrm{x}}$

[21] Alkhaldi T, Pranata I, Athauda RI (2016) A review of contemporary virtual and remote laboratory implementations: observations and findings. Journal of Computers in Education 3(3):329-351. https://doi.org/10.1007/s40692-016-0068-z 
[22] Tuttas J, Wagner B (2001) Distributed online laboratories. In: International Conference on Engineering Education, Oslo, Norway, pp 7-11

[23] De Jong T, Linn MC, Zacharia ZC (2013) Physical and virtual laboratories in science and engineering education. Science 340(6130):305-308. https://doi.org/10.1126/science. 1230579

[24] Azad AK (2011) Internet Accessible Remote Laboratories: Scalable E-Learning Tools for Engineering and Science Disciplines: Scalable E-Learning Tools for Engineering and Science Disciplines. IGI Global. https://doi.org/10.4018/978-1-61350-186-3.ch019

[25] Naddami A, Fahli A, Gourmaj M, Pester A, Oros R (2014) Importance of a network of online labs in magrebian countries. In: Remote Engineering and Virtual Instrumentation (REV), 2014 11th International Conference on, IEEE, pp 77-78. https://doi.org/10.1109/rev. 2014.6784227

[26] Waldrop MM (2013) The virtual lab. Nature 499(7458):268

[27] Pastor R, Hernández R, Ros S, Sanchez D, Caminero A, Robles A, Tobarra L, Castro M, Diaz G, Sancristobal E, et al. (2013) Online laboratories as a cloud service developed by students. In: Frontiers in Education Conference, 2013 IEEE, IEEE, pp 1081-1086 https://doi.org/10.1109/fie.2013.6684994

[28] Abdulwahed M, Nagy ZK (2011) The trilab and ilough-lab portal-systematic evaluation of the use of remote and virtual laboratories in engineering education. In: Computer Aided Chemical Engineering, vol 29, Elsevier, pp 1110-1114 https://doi.org/10.1016/b978-0-444$\underline{54298-4.50001-5}$

[29] Ince E, Güne ZÖ, Yaman Y, Kirbaşlar FG, Yolcu Ö, Yolcu E (2015) The effective $\neg$ ness of the iuvirlab on undergraduate studentsâĂŹ understanding of some physics concepts. Procedia-Social and Behavioral Sciences 195:1785-1792 https://doi.org/10.1016/j.sbspro. $\underline{2015.06 .382}$

[30] Lynch T, Ghergulescu I (2017) Newton virtual labs: Introduction and teacher per-spective. In: 2017 IEEE 17th International Conference on Advanced Learning Technologies (ICALT), IEEE, pp 343-345 https://doi.org/10.1109/icalt.2017.133

[31] Global Online Laboratory Consortium. [Online]. Available: http://www.online-engineering.org/GOLC about.php.

[32] Nedungadi P, Haridas M, Raman R (2015) Blending concept maps with online labs (olabs): Case study with biological science. In: Proceedings of the Third Internaᄀtional Symposium on Women in Computing and Informatics, ACM, pp 186-190 https://doi.org/10.1145/ 2791405.2791521

[33] Pegu UK (2014) Information and communication technology in higher education in india: Challenges and opportunities. International Journal of Information and Computation Technology 4(5):513-518

[34] Weller HG (1995) Diagnosing and altering three aristotelian alternative conceptions in dynamics: Microcomputer simulations of scientific models. Journal of Research in Science Teaching 32(3):271-290 https://doi.org/10.1002/tea.3660320307

[35] Achuthan K, Kolil VK, Diwakar S (2018) Using virtual laboratories in chemistry classrooms as interactive tools towards modifying alternate conceptions in molec $\neg$ ular symmetry. Education and Information Technologies pp 1-17 https://doi.org/10.1007/s10639-018-9727-1

[36] Achuthan K, Brahmanandan S, Bose LS (2015) Cognitive load management in mul-timedia enhanced interactive virtual laboratories. In: Advances in Intelligent In $\neg$ formatics, Springer, pp 143-155 https://doi.org/10.1007/978-3-319-11218-3 15

[37] Vadillo MA, Bárcena R, Matute H (2006) The internet as a research tool in the study of associative learning: An example from overshadowing. Behavioural processes 73(1):36-40 https://doi.org/10.1016/j.beproc.2006.01.014 
[38] Shih CF, Venkatesh A (2003) A comparative study of home computer adoption and use in three countries: Us, sweden, and india. Centre for Research on Information Technology and Organizations Retrieved August 1:2006

[39] Falloon G (2013) Young students using ipads: App design and content influences on their learning pathways. Computers \& Education 68:505-521 https://doi.org/10.1016/ j.compedu.2013.06.006

[40] Hung PH, Hwang GJ, Lin YF, Wu TH, Su IH (2013) Seamless connection between learning and assessment-applying progressive learning tasks in mobile ecology in $q$ quiry. Journal of Educational Technology \& Society 16(1)

[41] Ajzen I (1991) The theory of planned behavior. Organizational behavior and human decision processes 50(2):179-211 https://doi.org/10.1016/0749-5978(91)90020-t

[42] Davis FD, Bagozzi RP, Warshaw PR (1989) User acceptance of computer technology: a comparison of two theoretical models. Management science 35(8):982-1003

[43] Fishbein M, Ajzen I (1975) Belief, attitude, intention and behavior: An introduction to theory and research https://doi.org/10.1287/mnsc.35.8.982

[44] Moore GC, Benbasat I (1991) Development of an instrument to measure the pernceptions of adopting an information technology innovation. Information systems research 2(3):192222 https://doi.org/10.1287/isre.2.3.192

[45] Agarwal R (2000) Individual acceptance of information technologies. Framing the domains of IT management: Projecting the future through the past pp 85-104

[46] Rogers EM (1995) Diffusion of Innovations. Simon and Schuster, New York

[47] Sherry L, Gibson D (2002) The path to teacher leadership in educational technology. Contemporary issues in technology and teacher education 2(2):178-203

[48] Helitzer D, Heath D, Maltrud K, Sullivan E, Alverson D (2003) Assessing or pre 7 dicting adoption of telehealth using the diffusion of innovations theory: a practical example from a rural program in new mexico. Telemedicine Journal and e-health 9(2):179-187 https://doi.org/10.1089/153056203766437516

[49] Achuthan K, Bose LS, Francis S, Sreelatha K, Sreekala C, Nedungadi P, Raman R (2014) Improving perception of invisible phenomena in undergraduate physics education using ict. In: Information and Communication Technology (ICoICT), 2014 2nd International Conference on, IEEE, pp 226-231 https://doi.org/10.1109/icoict.2014.6914070

[50] Radhamani R, Sasidharakurup H, Sujatha G, Nair B, Achuthan K, Diwakar S (2014) Virtual labs improve studentâÁŹs performance in a classroom. In: International Conference on ELearning, E-Education, and Online Training, Springer, pp 138- 146 https://doi.org/10. 1007/978-3-319-13293-8_17

[51] Francis, S. P., Kanikkolil, V., Achuthan, K. (2016). Learning curve analysis for virtual laboratory experimentation. In 2016 International Conference on Advances in Computing, Communications and Informatics (ICACCI) (pp. 1073-1078). IEEE. https://doi.org/10. 1109/icacci.2016.7732187

[52] Diwakar S, Parasuram H, Medini C, Raman R, Nedungadi P, Wiertelak E, Srivastava S, Achuthan K, Nair B (2014a) Complementing neurophysiology education for developing countries via cost-effective virtual labs: case studies and classroom scenarios. Journal of undergraduate neuroscience education 12(2): A130 https://doi.org/10.5772/27864

[53] Diwakar S, Kumar D, Radhamani R, Nizar N, Nair B, Sasidharakurup H, Achuthan K (2015) Role of ICT-enabled virtual laboratories in biotechnology education: Case studies on blended and remote learning. In: Interactive Collaborative Learning (ICL), 2015 International Conference on, IEEE, pp 915-921 https://doi.org/10.1109/icl.2015.7318149

[54] Diwakar S, Radhamani R, Sujatha G, Sasidharakurup H, Shekhar A, Achuthan K, Nedungadi P, Raman R, Nair B (2014b) Usage and diffusion of biotechnology virtual labs for 
enhancing university education in india's urban and rural areas. In: E-learning as a sociocultural system: A multidimensional analysis, IGI Global, pp 63-83 https://doi.org/10. 4018/978-1-4666-6154-7.ch004

[55] Peansupap V, Walker DH (2006) Innovation diffusion at the implementation stage of a construction project: a case study of information communication technology. Construction management and economics 24(3):321-332 https://doi.org/10.1080/01446190500435317

[56] Jahanmir SF, Cavadas J (2018) Factors affecting late adoption of digital innovations. Journal of Business Research 88:337-343 https://doi.org/10.1016/j.jbusres.2018.01.058

[57] Easingwood, C., Harrington, S. (2002). Launching and re-launching high technology products. Technovation, 22(11), 657-666 https://doi.org/10.1016/s0166-4972(02)00097-4

[58] Peres, R., Muller, E., Mahajan, V. (2010). Innovation diffusion and new product growth models: A critical review and research directions. International journal of research in marketing, 27(2), 91-106. https://doi.org/10.1016/j.ijresmar.2009.12.012

[59] Goldenberg J, Han S, Lehmann DR, Hong JW (2009) The role of hubs in the adoption process. Journal of marketing 73(2):1-13

[60] Van Eck, P. S., Jager, W., Leeflang, P. S. (2011). Opinion leaders' role in innovation diffusion: A simulation study. Journal of Product Innovation Management, 28(2), 187-203. https://doi.org/10.1111/j.1540-5885.2011.00791.x

[61] Raman R, Nedungadi P, Achuthan K, Diwakar S (2011) Integrating collaboration and accessibility for deploying virtual labs using vlcap. International Transaction Journal of Engineering, Management, \& Applied Sciences \& Technologies 2(5):547-560

[62] Grajek, M., Kretschmer, T. (2012). Identifying critical mass in the global cellular telephony market. International Journal of Industrial Organization, 30(6), 496-507. https://doi.org/10.1016/j.ijindorg.2012.06.003

[63] Loch, C. H., Huberman, B. A. (1999). A punctuated-equilibrium model of technology diffusion. Management Science, 45(2), 160-177.https://doi.org/10.1287/mnsc.45.2. $\underline{160}$

[64] Bass FM (1963) A dynamic model of market share and sales behavior. In: Winter Conference American Marketing Association, pp 269-275.

\section{Authors}

Krishnashree Achuthan is the professor and dean of postgraduate programs at Amrita Vishwa Vidyapeetham, heads the Amrita Center for Cybersecurity Systems and Networks and Amrita Technology Business Incubator (Amrita TBI) at Amrita Vishwa Vidyapeetham. www.amrita.edu/faculty/krishnashree

Prema Nedungadi is the chairperson, computer Sciences, Amrita Vishwa Vidyapeetham and is a founding director at Amrita Center for Research in Analytics \& Technologies for Education (Amrita CREATE), an award winning, educational and health technology for societal benefit initiative of Amrita Vishwa Vidyapeetham, with $\$ 4.6 \mathrm{~m}$ in research funding, 2 patents and over 54 publications.www.amrita.edu/faculty/prema

Vysakh Kani Kolil is a researcher working at Amrita Center for Cybersecurity Systems and Networks, Amrita Vishwa Vidyapeetham associated with the Amrita Virtual Labs. www.vlab.amrita.edu

Shyam Diwakar is the Director, Computational Neuroscience and Neurophysiology labs, School of Biotechnology and an associate professor at Amrita Vishwa Vidyapeetham. He is currently the institute integration coordinator of Amrita Virtual Labs, a 
National Mission project developing online laboratories for University education. www.amrita.edu/faculty/shyam

Raghu Raman is the Director for Global Rankings \& Accreditation at Amrita Vishwa Vidyapeetham. His main research focus is in the areas of Diffusion of ICT Innovations in socio-technical systems, e-Governance, Big Data Analytics in Education and Health, Social Network Analysis and Virtual Interactive learning environments. www.amrita.edu/faculty/raghu

Article submitted 2019-09-16. Resubmitted 2020-05-24. Final acceptance 2020-05-26. Final version published as submitted by the authors. 